\title{
From Researching the Queering Potential of Music Therapy to Queering Music Therapy:
}

\section{an Unexpected Journey}

\author{
Julia Fent ${ }^{1}$ * \\ 1 University of Music and Performing Arts Vienna \\ *julia.fent@gmx.at \\ Received: 1 January 2019 Accepted: 4 October 2019 Published: 1 November 2019 \\ Editors: Candice Bain, Maevon Gumble Reviewers: Jennifer Swanson, Michael Viega
}

\begin{abstract}
In my article, I intend to trace the route from which the development and realization of an arts-based research project has led me. In this still ongoing project, I am aiming to explore in what way improvisation in music therapy fosters the emergence of ways of feeling and expressing that are excluded from hegemonic discourse and thus enables personal growth and development also in ways marginalized through certain societal norms. I started off with a theoretical concept merging psychoanalysis, queer theory, and music therapy theory and wanted to explore the specific potentials of musical action, which this concept entails. I chose an arts-based research style for this examination, as I intended not only to formulate and discuss these potentials, but also to focus on how they are experienced by individuals. I felt that, if I am interested in direct experience, I had to involve research methods that induce this experience - merely talking or thinking about them would not bring me far in that respect.

As the project is still ongoing, I cannot provide a final presentation of results here. However, there is already one result which I want to make the main topic of this article. Unexpectedly, in the course of the project I not only dealt with queering in respect to contents, but queering was also a process in which I found myself. In this article, I will elaborate why and how this happened.

I will first outline the motivation and development of the research project. Next, I will focus on the theoretical framework: first from the work of Julia Kristeva (1984/ 1974) - particularly Kristeva's conception of the subject as a sujet-en-procès (a subject-in-process) and the conception of different modes of meaning-making, and second from queer theory. Finally, I will elaborate on my personal experiences during the project which enabled me to critically examine music therapy in a way of 'queering' my understanding of music therapy.
\end{abstract}

Keywords: critical examination of music therapy, challenging of norms, power imbalances in clinical practice, participatory research, arts-based research 


\section{Introduction}

Before describing the project that inspired me to write this article, I will briefly outline what place it takes in my entire research and how it evolved from the work on my Ph.D. project.

I started working on my Ph.D. project at the University of Music and Performing Arts in Vienna (mdw) in 2016. I had completed a master's program in music therapy there several years before, yet my dissertation is within the discipline of gender studies. In my Ph.D. project, I initially intended to work in two directions. First, I wanted to analyze German language music therapy discourses from a critical perspective, involving theories from anti-discriminatory practice (for example, refer to Neil Thompson (2012/1992). I meant to trace what categorizations are performed, what valuations are assigned, how those perpetuate stereotypical attributions, and how all this influences music therapy practice. Second, I assumed a specific potential of music therapy therein; I argued that through music's extraverbal quality as realized in music therapeutic improvisation, it provides the possibility of experiencing and sharing qualities that go beyond verbal communicability and therefore allows for communication and encounters that go beyond discursive subject positions. The theoretical framework that led to this argumentation will be outlined later in this text.

In realizing my Ph.D. project, I started with the first aspect: a critical examination of music therapy theory and practice. I chose a participatory approach which was inspired by co-operative inquiry (Heron, 1996). A research group was formed consisting of myself and five other music therapists. Our aim was to examine how we experience categorizations and unchallenged assumptions in our own professional practice, how they can be made conscious, and how we might achieve alternative ways of thinking and acting. As this part of my research is completed by now, the next step in my critical examination will be to analyze texts, primarily from the area of the Viennese music therapy training, with the aim of tracing and systemizing unchallenged assumptions that can be found there in efforts to reveal how they are constructed and legitimized. For this, I will apply an approach of critical discourse analysis (Reisigl, 2011).

The above-mentioned research group ran from May 2018 to January 2019, including several meetings in that period. Conducting a co-operative inquiry, we were oriented towards a holistic understanding of knowledge generation. John Heron (1996) proposed that many possible forms of perception might be involved in an interplay between experience and reflection or between action and understanding. This meant that in our meetings we not only verbally discussed things but also listened to music, improvised together, and sometimes used writing and drawing as additional ways of action or reflection.

In this time, I had two important insights. First, I realized that in my Ph.D. project I will stick to only one of my initial aims - the critical examination. I became aware that researching a specific potential based on my theoretical framework needed to be omitted or done in a separate project. Second, although in our group sessions we engaged in non-verbal forms of knowledge generation, I realized that the methods I had chosen to analyze the video recordings of the sessions were not apt to analyze anything but verbal language. And, beyond that, I also realized that I did not want to search for other analyzing tools, as I thought it to be impossible to analyze another person's (or even my own) experience in a certain situation after-the-fact through assessing the way they made music in that situation. I will further explain this assumption later in this text.

Finally, these two insights led to the idea of conceptualizing a small project dealing with specific potentials music therapy might have but using a different research approach, one that involves artistic practice more thoroughly as it was the case in the cooperative inquiry and its subsequent evaluation. What came as a fortunate coincidence was that the University of Music and Performing Arts Vienna (mdw) is in a process of integrating arts-based research methods into its research activities. To foster that development, a call for projects was issued, which would enable the realization of small pilot projects. My project, which was designed in efforts of realizing what I had omit- 
ted from my PhD project, was chosen as one of the nine projects to be funded. ${ }^{1}$ This is the project I am primarily presenting in this article.

\section{An arts-based research project}

What is called "Künstlerische Forschung" in German language (at the mdw as well as by many authors writing in German language) can be directly translated as "Artistic Research" into English - yet, it is a conscious decision of the university to not yet determine terms and definitions in order not to narrow the possible research areas that might evolve from this new focus. So, existing debates on how artistic research may be defined, how it can be differentiated from arts-based research, how many and which other related concepts might exist, are observed and discussed at the mdw. Yet, there is no binding agreement on a common position in that. At the mdw, this special focus is added to scientific/scholarly research as a distinct "other" at the moment, yet this relationship will also be subject to further discussion. In German-speaking discourses on research in general, arts-based research is rather understood as a third possibility for research, complementing qualitative and quantitative research (Schreier, 2017).

In this article, I follow Michael Viega and Michele Forinash (2016) when I choose the term arts-based research. I also align myself with their understandings when considering the main characteristics of arts-based research. For example, I regard the fact that artistic processes are used as the central research method and as a means of examination, not merely as a means of stimulating a discussion or presenting research results, as this is often the case also in other forms of research. In my project, this has two implications: it meant either having a verbally formulated question as a point of departure and examining it through musical improvisation, or it meant starting off from a musical improvisation and developing into other forms of artistic expression, maybe talking about our experiences afterwards.

The research project consists of two major parts. First, Mischa Messner (a linguist), Vinko Nino Jaeger (a visual artist), and I became research partners and had several meetings, with Mischa and Nino joining me after I had already conceptualized the project. Here, the first one of the two above-mentioned possible implications was most common. Through musical improvisations, we worked on questions which we had posed ourselves in preceding discussions, expecting new insights from this artistic activity. These meetings had the overall aim of refining the theoretical framework and of designing methods for an event where we planned to involve more persons. It also was aimed at following the second of the above-mentioned implications (i.e., using musical improvisation as a starting point for further examination through other art forms).

Mischa, Nino, and I each relate to queer theory both in terms of the theory itself and in terms of our shared experience of being marked as different, of being marginalized, and of being denied fundamental rights. Further, we believe in the necessity to fight for visibility and justice. Additionally, we relate to music therapy in different ways. I am a trained music therapist with several years of clinical practice, Mischa is a linguist and is familiar with music therapy from a patient's ${ }^{2}$ position in several contexts, and Nino is a visual artist who also teaches in an arts therapy training course and had no experience with music therapy whatsoever before joining this project. While a commonality was found within our relationship to queer theory and the political actions that it might entail, the diversity of our relationship to music therapy allowed for a broadness that turned out to be a crucial ingredient. ${ }^{3}$

In this article, I am going to mainly elaborate on my experience during the first part of the project ? the meetings of the three of us. However, I want to briefly describe how we conceptualized the second part of the overall project, which then involved four more individuals. This second part was divided into three major stages, whereby the starting point of each was an improvisation that was then the issue of further exploration. In this way, we wanted to gain insights into improvisation, in cycles of experience and reflection involving various media. Improvisation was the theme of the 
process but also a methodological starting point involving music, dance/movement, and drawing.

For the first stage, we consciously decided to start with as open an approach as possible; we didn't want to initially talk about music therapy, but to open up a space for creative activity. The aim was to explore the materials in the room (i.e., space, musical instruments, paper, and pencils).

In the second stage, a short thematic introduction was given as an impulse; we deliberately did not want to dive into the underlying theoretical hypotheses in order not to leave the level of sensory experience too much in favor of theoretical discussions. Our introduction was therefore kept simple and roughly formulated as follows; we explained our observation that fundamentally different qualities than those of language are often attributed to music and other arts. Language would be rational; music would be emotional; language would be trapped in social norms; music would go beyond them, etc. We gave an example of the latter: the norm of a gender binary can be seen in language, for example, in the fact that (at least the German) language has only two pronouns for persons, male and female. This results from that norm and also stabilizes it continuously. As art is often said to be not bound by such restrictions because it is extra-verbal, it could theoretically be assumed that such norms could be transcended in musical activity. This led us to the next step: an invitation to try this out, to explore the possibilities of non-verbal expression through creative activity related to transcending or transgressing norms.

Finally, at the center of the third stage was musical improvisation as it is practiced in certain music therapy approaches. ${ }^{4}$ In contrast to the previous improvisations, in this part we established a common music therapy setting by sitting in a circle, selecting an instrument for ourselves, and then improvising together in a more regulated way than before. In the discussion that followed, the focus was on the question of whether and how this improvisation was experienced differently from the previous ones. By this, we wanted to make unquestioned conventions and norms of music therapy the topic, which became clearer against the background of the previous less regulated improvisations. Even though my educational background in music therapy likes to speak of "free improvisations", there are certain conditions due to the specific, often clinical situations alone which cause a number of restrictions and unspoken regulations.

This second part of the project took place in May 2019, but it has not yet been evaluated and therefore I cannot present the results of this part yet. ${ }^{5}$

\section{Theoretical framework}

I will now introduce the theoretical framework for the arts-based research project. As already mentioned, I am aiming to explore the question of whether and how improvisation in music therapy might foster ways of feeling and expression that are excluded from hegemonic discourse and might thus enable personal growth and development, also in ways which are marginalized by certain societal norms. These norms can be found in different aspects of a person's personality; someone's gender, race, or class identification, for example, influences their personal style, habits, manner, capacities, or professional choices due to the societal norms bound to this identification and the power relations asserting them.

As a theoretical starting point, I chose Julia Kristeva's (1984/1974) considerations on subjectivity and meaning-making, considering them to be integrative and particularly connectable to the conception of music therapy, relevant to me through its psychoanalytical foundation on the one hand and to poststructuralist discourses and queer theory through the specific subject construction of the sujet-en-procès on the other. Kristeva's work also shaped my understanding of music therapy in this project.

Kristeva's ideas are based on psychoanalytical theory as it was formulated by Sigmund Freud, Jacques Lacan, and others. When stating that the emergence of the child as a socially perceivable subject accompanies the child's acquisition of language, Kristeva followed one of Lacan's (1953) central ideas, the mirror stage. In this period of 
time - between 8 and 15 months of age - children recognize the mirror image as an image of themselves and thus identify with it. This is the beginning of a process of subjectification which enables an external view of oneself and which, accompanied by language acquisition, finds its continuation in the child's entry into the "symbolic order" of the world. Kristeva conceptualizes this process as "thesis," where the detachment of the child from the semiotic ${ }^{6}$ chora takes place. The semiotic chora is difficult to describe. It is not a place nor a bodily or material unit, but it is free-floating energy, strongly connected with body sensations, and it is not bound to societal norms of any kind. It is not carrying meaning, but it is the enabling condition of all meaning.

After this detachment, children perceive themselves as subjects distinctly different from others. The way in which they are able to live out this subjectivity is regulated by the "symbolic order," which is constituted of a society's hegemonic ideas and norms and, therefore, excludes what is excluded by those. ${ }^{7}$ Kristeva named the mode of giving meaning, which from then on prevails, as the "symbolic" and calls the one that marks the time before language acquisition the "semiotic."

This is a point where Kristeva's concept clearly differs from Lacan's. In Lacan's (1953) view, the form of meaning making which prevails after the mirror stage is more mature in comparison to that which is accessible to the child before, which Lacan understands as being overcome and no longer relevant afterwards. Kristeva instead did not adopt this classification, stating that the functioning of the semiotic is not lost with the entry into the symbolic order but that it constantly influences the symbolic and destabilizes it. Thus, subjectification is also a constant process that can never be completed, as the subject is in a continuous process of change through the interplay of the semiotic and the symbolic, as is society as a whole. This is the revolutionary force Kristeva devotes to the semiotic.

I consider Kristeva's conception of the subject to be a non-essentialist one, as it is a subject that is never stable and is in a continuous process of negotiating societal norms on the one hand and personality aspects excluded by them on the other. This is the point where I recognize a strong parallel to queer theory. ${ }^{8}$ Similar to Kristeva's work, queer theory also emphasizes identity and subjectivity as fluid - a fluidity which is not understood as a threat but quite the contrary; it is inherent in being human, and the denial of it leads to the exclusion of individuals who do not identify within the boundaries of hegemonic norms asserting only selected, rigid forms of identification.

Queer theory challenges normative concepts, stating that anything perceived as "normal" or "natural" by certain people in a certain time and place receives this quality only as a result of certain processes of construction. In Judith Butler's (1990) Gender Trouble, John Austin's (1962) speech act theory served as the starting point to explain the construction of gender. Speech acts, as performative acts, do not make statements or descriptions, but they create the reality that they comprise. An example would be the midwife's or doctor's statement at the birth of a child: "It's a girl!" This is not a mere description of what they perceive and interpret as female, but brings this reality into being - to be classified as female means for the child to be treated and dressed in certain ways, to be confronted with specific expectations and attributions from outside. All this is shaped by the hegemonic view of femininity of the respective society, offering rigid conceptions of a number of possible identifications people might either live up to or be marginalized or denied their way of identifying.

Here, Butler referred to Michel Foucault (1970/1966). According to Foucault, discourses - described as the entirety of the statements on a certain subject area - are not descriptions of reality, but instead create the preconditions for how it develops or is shaped by people. Thus, it is also discourse that produces gender and subjectivity. Foucault was particularly interested in the question of which norms were effective at different times and how claims to power and domination were constructed and asserted, as well as their variability and discontinuities. According to Foucault, history proves that truth and knowledge are not universal but dependent on the respective epochs and their power structures, processes of knowledge production are constructive. Sciences and professions that allegedly serve people, such as the human sciences from the 19th 
century onwards (for example, psychology and pedagogy), also aim to discipline us by creating norms and means to shape people's behavior by marginalizing and pathologizing those who do not correspond to these norms (Foucault, 1977/1975). Foucault analyzed power relations not only on a state level but also in microstructures, that is, in hierarchized relationships, such as between men and women, teachers and pupils, doctors and patients.

Judith Butler (1993) also emphasized that concepts only acquire their meaning through permanent iterations and citations, which never allows them to be stable in their meaning. It is then precisely this instability that holds the potential for change and subversion. Similar to this, Julia Kristeva (1984/1974) recognized a revolutionary force in the semiotic's ability to keep subjects - and society as a whole - in a continuous process of change and rearrangement by continually challenging the symbolic. Kristeva elaborated on how this force can be consciously used by analyzing literature from Comte de Lautréamont, Stéphane Mallarmé, James Joyce, and others. By destabilizing actions like transcending language's norms regarding grammar, syntax, genre, etc., or through analogous processes in other artistic media and practices, it is possible to reconstruct the semiotic chora and thus bring the functioning of the semiotic within the symbolic to its surface. Such an approach seeks to expand the symbolic order by destabilizing it - a strategy that is also recognized as a means of fighting normativity in queer theory. Judith Butler (1997), for example, conceptualized a post-sovereign subject in such a way that individuals can only gain agency by becoming aware that they are inescapably shaped by hegemonic discourse and that they might change its continuation - and thus themselves - by recourse to alternative discourses.

Additionally, Kristeva's (1984/1974) ideas about the potentials of certain artistic practices provide a possible framework for understanding improvisation in music therapy. ${ }^{9}$ In this sense, improvisation, as practiced in music therapy, can be understood as an approach to music that is particularly suitable for a practice such as that outlined above - in contrast to the performance of a concert, for example, which, like everything else, has semiotic components in itself but does not strive for destabilization and consciously acts according to a number of norms. In music therapy improvisation, however, regulations regarding harmony, musical form, genre, and so on do not have to be applied (or even known). Free creativity and originality are strongly welcomed; the emergence of what was hitherto unknown is expressly intended. Furthermore, in therapeutic situations, structure and setting are offered as a means of security to enable persons to engage in such an adventure.

Using Kristeva's (1984/1974) conception of the semiotic and the symbolic as two different but always intertwined ways of meaning-making also provides opportunity to unsettle a dichotomy often found in music therapy: the dichotomy of music and spoken language as two fundamentally different ways of expression. With Kristeva, it is clear that all kinds of expression contain both symbolic and semiotic meaning-making processes, but with different weight. Following Randi Rolvsjord's (2004) remarks on the topic, I suggest that improvisation in music therapy can be recognized as a way of music-making that is strongly dominated by semiotic forms of meaning-making. Based on these considerations, I therefore assumed at the beginning of my research project that improvisation could enable the emergence of qualities and aspects of a person that are excluded from hegemonic discourse - meaning the emergence of semiotic qualities within the symbolic.

Finally, I will briefly outline my understanding of queering in this context. For me, queering is, in the first place, the shifting of norms. Norms concerning identity often appear in dichotomous constructions. In that sense, queering involves actively questioning dichotomous constructions such as gender (male/female), race (Black/White), class (rich/poor), but also dichotomies like the one mentioned above (music/spoken language). Dichotomies cannot possibly cover all possibilities of experience, and the distinction between two poles in a dichotomy relies on a society's hegemonic conventions. Queering, to me, also involves an opening up to ways of being, moving, feeling, and defining oneself (if only temporarily) or one's actions beyond dichotomous con- 
structions. Furthermore, in dichotomies as given above, usually one pole is regarded as the norm, the other as the deviation. The first is also equipped with more power, the second with less. Queering can therefore not be separated from power relations, which stabilize societal norms in the interest of hegemonic societal groups.

Thus, when trying to consider the potential of music therapy in providing understandings of identities that have been excluded by certain societal norms, one has to keep in mind that music therapy practice is situated in contexts that might exclude, pathologize or produce inequalities. Becoming aware of imperceptible norms and identifying whose interests they serve is another important aspect of queering.

\section{Main insights}

I now want to briefly outline how my own focus was gradually broadened during the project. The initial aim of the overall project that I have outlined was complemented by my increasing awareness of how important it is for me to critically examine my foundational understanding of music therapy.

This was largely made possible by the fact that neither of my two research partners were music therapists, and one of them even had no experience of or knowledge about music therapy whatsoever. This had a crucial advantage in that, up to that point, I had only critically examined music therapy practice with colleagues who were also music therapists. Within my Ph.D. project, all the research among us, although self-critical, was done from within the boundaries of our music therapy training, our professional experience, and our identities as music therapists. Without us even noticing, this confined our potential for questioning theories and practices to certain boundaries, which were defined by norms and conventions in music therapy as we knew it. Examples of these norms and conventions might be certainly defined procedures in music therapy sessions: how sessions are opened, how improvisations are initiated, which instruments are offered, which room settings are considered appropriate, and many more. Many of these choices seem self-evident even to critical music therapists, as they are so deeply grounded in the approach to music therapy that was predominant in the music therapy training they received.

In the arts-based research project, in contrary, I now have the opportunity to conduct an in-depth examination of music therapy alongside people from outside the field of music therapy, which has caused me to question things that I had until then taken for granted. It led me to increasingly recognize and examine the often imperceptible norms which are frequently unquestioned in music therapy. I consider this a queering of my understanding of music therapy.

For me, the first improvisations in the initial group of three were very striking: I was able to learn, with greater depth, how as a therapist, I think and feel about the musical expression of others. I often noticed that I began to classify/interpret things given that I was used to doing this as a therapist in a clinical setting. But then, thoughts like the following came up: no, these are not patients, I don't want to think this way about them, this is intrusive, insulting. This led me to the questions: What is the role of the patient in relation to the therapist? Why do I judge a musical utterance differently depending on what position the other person has in relation to me or what kind of relationship we have? How much of my impression is due to the musical interaction and how much to the division of roles or power relations in that situation? How much does my impression have to do with the other person at all? In my considerations, I came to the conclusion that the division of roles has a great influence on my perception of my counterpart. To be a patient in a clinical setting means that THIS is the person who is in need of change; musical and other utterances are therefore automatically examined as, for example, potential starting points for further therapeutic work or as evidence for pathologies. Even if they are examined in a positive way for coping mechanisms and even if the therapist is grounded in a resource orientation, the patient remains the object of observation in this role, and everything observed is perceived as originating from them. 
An example for this would also be the concept of resistance. A patient's resistance is often taken as an opportunity to deal with the patient's supposed problems, which allegedly led to this resistance to/in music therapy. In my experience, it is less frequently asked on this occasion whether music therapy is a suitable type of therapy for the patient or whether therapy helps them at all. Further, it is often not considered if, due to the personalities or other characteristics of both therapist and patient, merely the combination of the two might be difficult. A patient's resistance in music therapy is perhaps rarely understood as positive in some respect, meaning that the situation is most often considered as a problem and is automatically understood as originating from the patient.

Even though in my former clinical practice I had often questioned the clinical setting, this direct experience of my thoughts and emotions in our improvisations was still surprising and impressive to me. The change of perspective which was caused by this particular approach to researching music therapy was very fruitful for me. We acted in a way which is common in therapeutic or supervisory contexts; however, the "test" was not for one of the people involved but of the music therapy process itself. I consider such an experience to be very valuable for music therapists, because it might help us to recognize how determined we are as therapists by our concepts and diverse attributions to patients and their music. Additionally, it suggested to me that those assumptions often do not help us to learn more about the people with whom we work but are an actualization and confirmation of social norms in relation to the status of therapist and patient. These assumptions thus continue pathologization.

For example, psychopathology played an important role in my music therapy training, ${ }^{10}$ and it is common to draw conclusions about a person's personality and "pathology" based on the way they use musical instruments. Ascribing whatever observations I have about a person, to an aspect of them I know or assume, has long been something I cognitively understood as determining. Therefore, I rejected this idea. Nevertheless, this project has showed me that, in spite of my good intentions, I still do this a lot. It became even clearer to me that having a strong focus on a person's personality structure and behavior narrows my ability to observe and evaluate, as I easily attach my perceptions as originating from there. Improvising with persons who are not patients made this very clear to me, as I took into account a lot of other factors that influence a person's way of playing an instrument (e.g., their familiarity with the musical instrument, with playing music overall, etc.). I do not think that it is necessary or even possible to NOT have a focus, but I do think that therapists need to be aware of their assumptions and consider that there could perhaps be other reasons behind what they are observing other than that which they assumed in the first moment.

This project also caused me to think about music therapy research, especially case studies. Case studies are used for the evaluation of therapy processes and their scholarly exploitation in order to record a patient's progress through the analysis of musical events and make it comprehensible to others. I do not wish to reject these practices, which are sometimes very demanding and complex. However, against the background of the concept of different modes of meaning-making explained above, it causes me to think that, in most of these procedures, it is external researchers - people who have not been involved in the improvisation - who draw conclusions from the music they hear about what was happening or what was the condition of the individuals during the improvisation. If now I assume, however, that the process during an improvisation is mainly determined by the semiotic, then there are yet to be any units of meaning there in regards to what the general agreement is (i.e., what the external researchers associate with them has primarily to do with them, at least in terms of the words used to express it being exclusively their own). Certain approaches therefore seek, in complex analytical steps, to grasp the core of meaning behind the words (e.g., through a poetic approach to language). Now, of course, the subjectivity of the researchers plays a role in all research. What makes me somewhat dissatisfied, however, is when - and this is my impression - researchers then assume a sovereignty of interpretation and claim to be able to make statements about the experience of those who have been in- 
volved in the improvisation via their own resonance with the predominantly semiotic events in an improvisation. For me, these approaches are even more problematic in a therapeutic framework, as this invokes the roles of therapist and patient with all the power relations, mechanisms of pathologization and claims to interpretational sovereignty that this brings along.

\section{Conclusion}

In conclusion, the most striking outcome of this project was, for me, that from starting with the intention to realize a queering potential in music therapy, the project led us to a queering of music therapy itself. By shifting perspectives, imperceptible norms could become perceptible; it became obvious how much my perceptions (as a therapist) of people in a therapeutic interaction are defined by the power relations within therapeutic relationships where one person is marked as the therapist and one marked as the patient. For me, this provides a hint into the importance of shifting perspectives, and in particular, embracing perspectives that originate from outside the field of music therapy, especially in a clinical context. As the composition of the persons I improvised with was a decisive factor for me, this might also provide impulses regarding the composition of supervision groups. These findings also perhaps emphasize that the involvement of creative processes and sensory experience as a means of examination and research is important in that respect. All in all, I expect the use of similar approaches in research as well as in clinical supervision to be beneficial both for therapists and for patients, as well as for society as a whole, as it might help to undermine stereotypes, decrease marginalization, and shift unequal power relations.

\section{About the author}

Julia Fent holds degrees in singing (Prayner Conservatory Vienna, Austria) and music therapy (mdw - University of Music and Performing Arts Vienna, Austria) and is currently a Doctoral candidate at the mdw - University of Music and Performing Arts Vienna (Gender Studies).

Funded projects at the mdw: Emergence of the Excluded - Post-Sovereign Subjects in Music Therapy (funded by the Office of Research Support) and Musiktherapie querdenken - Einladung zum Perspektivenwechsel (funded by the Administrative Department for Equality, Gender Studies \& Diversity).

Research interests: Critical perspectives on music therapy theory and practice, antidiscriminatory practice, queer theory, critical discourse analysis, participatory research.

\section{References}

\section{Notes}

1. I would like to thank the Office of Research Support at the University of Music and Performing Arts Vienna for the possibility of realizing the project through their funding.

2. In this paper, I use the word 'patient' for participants in music therapy who are not therapists, as it is the word used most frequently in Austria, where music therapy has a strong tradition in clinical settings. I will critically examine the implications the word entails but do not want to generally replace it, as this would mean disguising the underlying power relations.

3. Obviously, this broadness was not only crucial for the further development of the research project but will also guarantee a multi-perspectival view on the project in the final documentation and evaluation. This article is therefore only one contribution to this evaluation, providing my personal reflections and experiences during the project from my specific perspective as a music therapist. 
4. For example, the one taught in the training course at the University of Music and Performing Arts Vienna, which sees itself to be "psychotherapeutically oriented," positioning centrally the therapeutic relationship between therapist and patient.

5. Nevertheless, I want to very briefly sketch my impression from the larger group event in relation to the initial aim of the research project (i.e., researching a queering potential in music therapy). When thoroughly evaluating the larger group event, of course, not only my impressions and ideas but those of all people involved would have to receive attention. At this point, I would say that definitely more thinking and experimenting would be needed to further elaborate on this question. I would - very reluctantly - assume that a conventional music therapy setting might not be, for several reasons, the environment in which this potential could emerge. It is perhaps only a setting where power relations and perspectives, as well as conventions and norms, in each situation and grouping are constantly critically examined where certain forms of improvisation could bear a queering potential. The possible qualities of this kind of queering potential would have to be the topic of a possible future research project, as this turned out to be beyond our time limits in this project.

6. The terms semiotic and symbolic are used a lot throughout this article and are terms that bear a lot of multiple and different meanings in different various contexts. I use them only in the meaning outlined in the article, referring to Julia Kristeva's conception of the terms.

7. The idea of persons becoming intelligible subjects only insofar as they live up to a society's hegemonic norms is an idea which has also been elaborated by Judith Butler (1990).

8. Relating Kristeva's ideas to queer theory is, of course, only possible if a non-essentialist view of the semiotic and symbolic is adopted. At first, this may not be so easy to approach, as in many contexts Kristeva's semiotic has been denoted as a female modality, supposedly due to the fact that Kristeva associates the semiotic chora with the mother's body. Some authors (for example, refer to Toril Moi, 1985) nevertheless state that a non-essentialist understanding of Kristeva's ideas is the most logical conclusion, or at least one possible view due to Kristeva's fluid conception of identity, where the subject is never stable and in a continuous process of redefining itself.

9. The possibility of using Kristeva's conceptualization of the semiotic and the symbolic as a framework for understanding music therapy has already been acknowledged by Randi Rolvsjord (2004).

10. I have to state that many music therapists also in Austria are critical about pathologization and diagnostic manuals. Nevertheless, they see this as an important basis for communication within an interdisciplinary team, for example.

\section{References}

Austin, J. L. (1962). The William James Lectures delivered at Harvard University in 1955. Oxford, GBR: Clarendon Press.

Butler, J. (1990). Gender Trouble: Feminism and the Subversion of Identity. New York, NY: Routledge.

Butler, J. (1993). Bodies That Matter: On the Discursive Limits of "Sex". New York, NY: Routledge.

Butler, J. (1997). Excitable Speech: A Politics of the Performative. New York, NY: Routledge.

Foucault, M. (1970/1966). The Order of Things: An Archaeology of the Human Sciences. New York, NY: Pantheon Books.

Foucault, M. (1977/1975). Discipline and Punish: The birth of the Prison. New York, NY: Random House.

Heron, J. (1996). Co-operative Inquiry. Research into the Human Condition. London, GBR: Sage.

Kristeva, J. (1984/1974). Revolution in Poetic Language. New York, NY: Columbia University Press.

Lacan, J. (1953). Some Reflections on the Ego. The International Journal of Psychoanalysis, 34(1), 11-17. 
Moi, T. (1985). Sexual/Textual Politics: Feminist Literary Theory. London, GBR: Routledge.

Reisigl, M. (2011). Grundzüge der Wiener Kritischen Diskursanalyse. [Basics of Viennese Critical Discourse Analysis]. Handbuch Sozialwissenschaftliche Diskursanalyse. Volume 1: Theorien und Methoden, 1(3), 459-497.

Rolvsjord, R. (2004). Music as a Poetic Language. Voices: A World Forum for Music Therapy, 4(1), https://doi.org/10.15845/voices.v4i1.141.

Schreier, M. (2017). Kontexte qualitativer Sozialforschung: Arts-Based Research, Mixed Methods und Emergent Methods. [Contexts of Qualitative Research: Arts-Based Research, Mixed Methods, and Emergent Methods]. Forum Qualitative Sozialforschung, 18(2), http://dx.doi.org/10.17169/fqs-18.2.2815.

Thompson, N. (2012/1992). Anti-discriminatory Practice. Equality, Diversity and Social Justice. (5th ed.) Basingstoke, GBR: Palgrave Macmillan.

Viega, M., \& Forinash, M. (2016). Arts-Based Research. In B. Wheeler \& K. Murphy (Eds.), Music therapy research (3rd ed., pp. 784-804). Dallas, TX: Barcelona. 